\title{
Erosive Wear Assessment of Sandstorm on the Strength Properties of Automobile Glass
}

\author{
*S.S. Owoeye*, Y.D. Lamidi, O.J. Ajayi \\ Department of Glass and Ceramic Technology, Federal Polytechnic, Ado-Ekiti, P.M.B. 5351, Nigeria
}

\begin{abstract}
In order to assess the extent of sandstorms effect on automobile glass in the area mostly prone to sandstorms phenomena typical of the Northern part of Nigeria, sandblasting tests were conducted in laboratory on a laminated soda lime glass of $300 \mathrm{~mm} \times 300 \mathrm{~mm}$ with standard automobile glass thickness of $4 \mathrm{~mm}$ each and PVB film of $1 \mathrm{~mm}$. The sand particles were projected by sandblasting machine with an air flow speed of $54 \mathrm{~km} / \mathrm{hr}$ $(15 \mathrm{~m} / \mathrm{s})$ and the impact angle was fixed at $90^{\circ}$ while the blasting duration and distance of impingement was $60 \mathrm{secs}, 180 \mathrm{secs}, 300 \mathrm{secs}$ and $60 \mathrm{~cm}, 40 \mathrm{~cm}$, and $20 \mathrm{~cm}$ respectively. The erosion tests carried out show significant drop in impact strength, and flexural strength.
\end{abstract}

Keywords: Sandblasting, Sandstorms, Automobile glass, Impact strength, Flexural Strength.

\section{Introduction}

In Saharan regions, where sandstorm phenomena is mostly observed; the devastating effect is not only on the rural and urban environment but also on the brittle materials most especially glass products such as home windows' glass, windshields, solar panel protective glass, headlamps of vehicles, and vehicles' windscreen. The glass surfaces are deteriorated by the impact of fine sand particles of different shapes carried by the wind. The material removal caused by these continuous and repetitive impacts can be detrimental to the overall mechanical and optical properties of the glass. This kind of solid particles erosion on soda-lime glass surface results into various superficial defects like micro cracks, scaling, and crater that reduce transmission of light by blurring and causes strength reduction of glass [1-4]. Based on literature, the impacts of sand particles causes elastic-plastic features in which lateral cracks are responsible for the removal of material, this occurs by chipping when lateral cracks interact with each other and with the glass surface [2,3]. The lateral cracks result into mass loss through scaling mechanism while reduction in mechanical properties resulted from radial cracks [5, 7]. Hutchings [6] and several other researchers [7,-9] have carried out investigations on the erosion of brittle materials for explaining or modeling the phenomena observed during sandstorms indicating parameters such as properties of incident particles (which include size, shape, density, hardness), properties of target materials (which include hardness, surface state, and fracture toughness), and test conditions (which include impact angle, impact velocity, and temperature) as factors that are responsible for the erosion of brittle materials. [1011] also revealed that the kinetic energy transferred when glass is subjected to erosion is significant for measuring the erosion of brittle. The authors further showed by experiment that for a glass subjected to erosion, a 100 Joules of energy is required for tearing a quantity of matter with surface area range of $1 \mathrm{~cm}^{2}$ and a depth of $1 \mathrm{~mm}$.

Mahdaoui et al [12] also investigated on the effects of sandblasting on soda lime glass erosion intended for vehicles windshields manufacture. In their studies, the erosive wear of soda lime glass was evaluated at different impingement angles, with varying sand masses, and three different velocities. The results obtained show that the erosion rate (Er), the mean roughness $(\mathrm{Ra})$ and the mass loss $(\Delta \mathrm{m})$ reach their maximum at $90^{\circ}$ (flow normal to the surface). After exposure to a sand mass of $300 \mathrm{~g}$ at normal incidence, the glass surface becomes totally blurred. From these observations, it was noticed that the erosion mechanism is often of a brittle kind characterized by the formation of radial and lateral cracks that develop into chippings. Recently, Bellies et al [13] further shows failure mechanisms and residual capacity of annealed glass/SGP laminated beams at room temperature, they compared (PVB) with stiffer and stronger interlayer sentry glass plus (SGP). After breakage of both glass sheets the load decreased to a relatively low level (typically between $2 \mathrm{kN}$ and $3 \mathrm{kN}$ ) before the broken glass pieces and interlayer started again to build up compressive and tensile stresses, 
respectively. Subsequently, the load slightly increased again and after reaching the maximum, it decreased significantly (to less than $0.3 \mathrm{kN}$ ).

Zang et al [14] also investigated on impact fracture behavior of automobile laminated glass by 3D discrete element method. The authors' investigation focused on the use of the $3 \mathrm{D}$ discrete element method to study the impact fracture problem of laminated glass. The glass and the (PVB) of laminated glass plane are discretized to uniform rigid spherical elements. This investigation showed that the accuracy of the $3 \mathrm{D}$ model and numerical analysis code are more validated in the elastic range by comparing with FEM.

Keller [15] also measured the delaminating energy in laminated safety glass, used novel method to measure the delaminating energy in laminated glass in the relevant dynamic range. He found that increasing the thickness of the interlayer improves the resistance to penetration of laminated glass because more energy can be absorbed in the high speed delimitation process since the interlayer is simply less like to tear.

Laminated glass is a type of glass which consists of two or more glass panes bind together with a thin interlayer, Polyvinyl Butyral (PVB) in an autoclave under elevated temperature and pressure which prevents the glass from separation incase of breakage [16]. Aside the safety measure, laminated can also ensures thermal insulation, sound insulation, ultraviolet radiation adsorption, and moisture insensitivity which make the glass popular in many architectural glazing and also in automobile industry [17].

In this research work, erosive wear assessment of automobile glass (windscreen) was investigated under laboratory simulation using sandblasting process. Parameters such as impact angle, impact velocity, impact distance, sand mass, sand sizes were all put into considerations.

\section{Experimental Procedure}

\subsection{Characteristics of Sand}

The eroding sand particles used in the course of this research were silica sand gotten from the beach area of Nigeria which are typical representation of sands generated during sandstorms in the Northern part of the country. The sands have a range size of 0.15-0.3 mm with particle shapes varying from spherical to angular which is peculiar to most eroding sand particles. The hardness and fracture toughness determination was based on the literature values given by some authors [18-22] as stated by
[4] in the Table 1. The blasting sand used in the study therefore conforms to the silica sand having hardness of $11.2 \mathrm{GPa}$ and fracture toughness of 1.2 $\mathrm{MPa} \cdot \mathrm{m}^{1 / 2}$.

Table 1. Some values of hardness and fracture toughness of silica sand [14-18].

\begin{tabular}{|c|c|c|}
\hline Particle material & Hv $(\mathbf{G P a})$ & $\mathbf{K}_{\mathbf{1 c}}\left(\mathbf{M P a . m}^{\mathbf{1 / 2}}\right)$ \\
\hline Silica (Quartz) & 13.1 & 1.4 \\
\hline Silica sand & 35.3 & - \\
\hline Silica sand & 11.0 & 1.2 \\
\hline Natural Quartz & $\approx 6$ & $\approx 0.7$ \\
\hline Silica sand & 13 & 1.3 \\
\hline
\end{tabular}

\subsection{Glass Characteristics and Sample Preparation}

The target material used in the course of this research is a $4 \mathrm{~mm}$ thick soda lime glass sheet. The chemical composition of the glass is majorly $72.3 \%$ $\mathrm{SiO}_{2}, 6.7 \% \mathrm{CaO}$, and $14.7 \% \mathrm{Na}_{2} \mathrm{O}$ as stated by [23]. The glass sheet was cut into 300 x $300 \mathrm{~mm}$. $1 \mathrm{~mm}$ thick PVB interlayer were placed in between the cut samples, the assembly is then heated to about $70^{\circ} \mathrm{C}$ and pressed by roller process to squeeze out the air or blisters (pre-lamination). Further heating was carried out for proper lamination at a temperature of $140^{\circ} \mathrm{C}$ under a pressure of about $0.8 \mathrm{MPa}$. A total number of 15 laminated glass samples measuring 300 x 300 x 9mm were therefore produced for sand blasting procedures. The samples were divided into three: Sample A, B, and $C$ respectively. Samples $A$ is to be sandblasted for 60 seconds, Samples B for 180 seconds, and Samples C for 300 seconds.

\subsection{Sandblasting Process}

Depending on the velocities of impact, several erosion test rigs have been stated in the literature according to [24-25]. A horizontal jet impingement system was used in this research as recommended by the standard of airborne particles erosion tests according to ASTM G76-89 as stated by [4]. The horizontal impingement system comprises of an ejector in form of an elongated cylindrical having a conical convergent end which allow regular particles suction. The air speed for projecting the sand particles in this research was fixed at $15 \mathrm{~m} / \mathrm{s}$. The erosion tests were carried out under the following conditions:

\section{Fixed Parameters:}

- Speed of air: $15 \mathrm{~m} / \mathrm{s}(54 \mathrm{~km} / \mathrm{hr})$

- Sand grain size: $0.15-0.3 \mathrm{~mm}$

- Dimension of laminated glass: 300 x 300 x $9 \mathrm{~mm}$ 
- Impact angle: $90^{\circ}$

Variable Parameters:

- Time duration: 60secs, 180secs, and 300 secs respectively

- Distance of the nozzle to glass sample: $60 \mathrm{~cm}$, $40 \mathrm{~cm}$, and $20 \mathrm{~cm}$ respectively.

The sandblasting process was carried out by exposing the sample glasses A, B, and C respectively to sand impingement. Samples A were sandblasted for 60 seconds at a distance of $60 \mathrm{~cm}$ from the nozzle while Samples B were exposed to sand flux for 180 seconds at a distance of $40 \mathrm{~cm}$ from the nozzle, and Samples C were sandblasted for 300 seconds at a distance of $20 \mathrm{~cm}$ respectively as shown in figure 1 . The sandstorms effects make the sample glasses to be highly blurred as a result of surface roughness as shown in figures 2 .

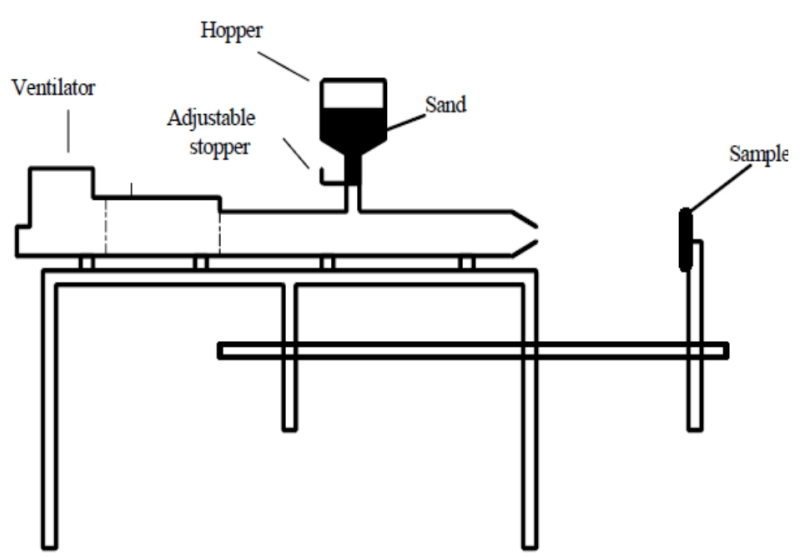

Fig. 1. Sand jet impingement set up according to [19]

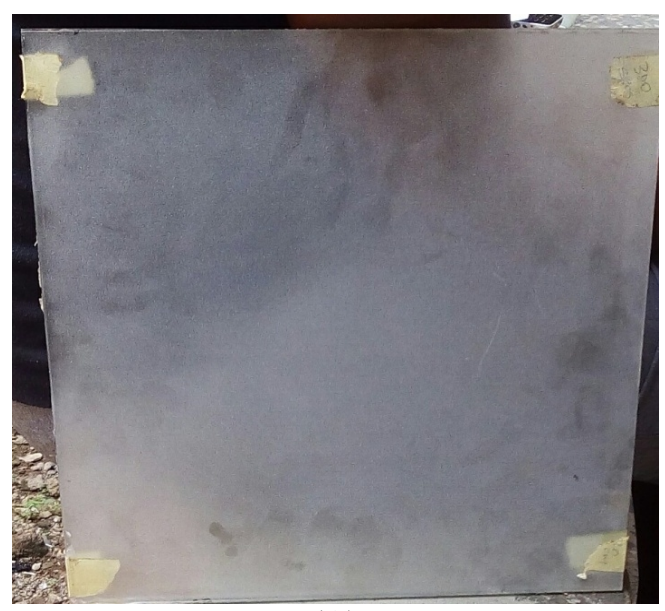

(A)

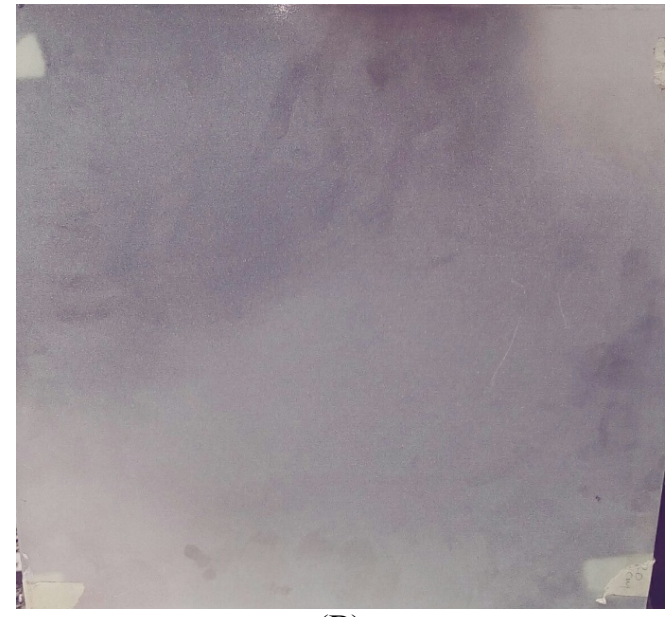

(B)

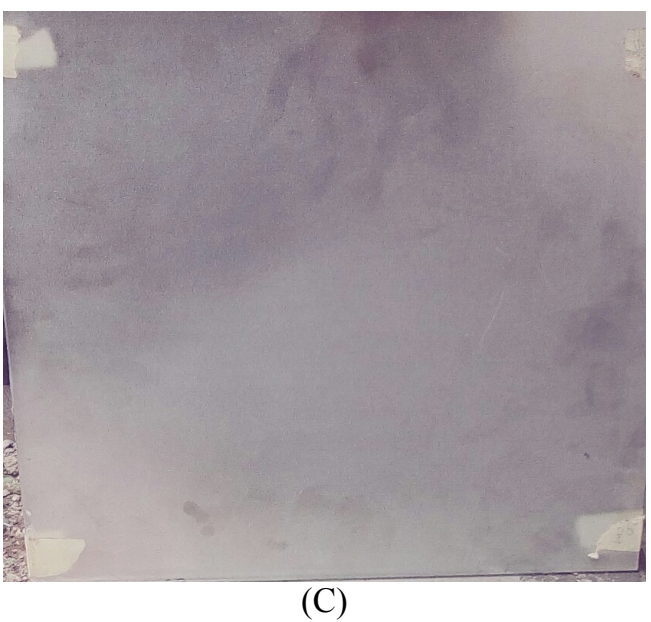

Fig. 2. Sandblasted glasses of (A) 60secs, (B) 180secs, and (C) 300 secs

\section{Measurements}

Measurements such as impact test, flexural strength test were carried out and analyzed to assess the erosive effects of sandstorms simulated by sandblasting operation on the strength properties of the laminated safety glass intended for automobile glass.

\subsection{Impact Test}

The impact test was carried out using the Ball Drop Impact Method. The sample glasses A,B, and C were place on a flat surface and different ball masses of $100 \mathrm{~g}, 200 \mathrm{~g}$, and $250 \mathrm{~g}$ was allowed to fall from different distances of $60 \mathrm{~cm}, 40 \mathrm{~cm}$, and $20 \mathrm{~cm}$ respectively on the glass surface to make an impact until breakage was observed as shown in figures 3 revealing their breaking pattern. The average impact energy was then calculated for each sandblasted sample glasses from the obtained readings. 


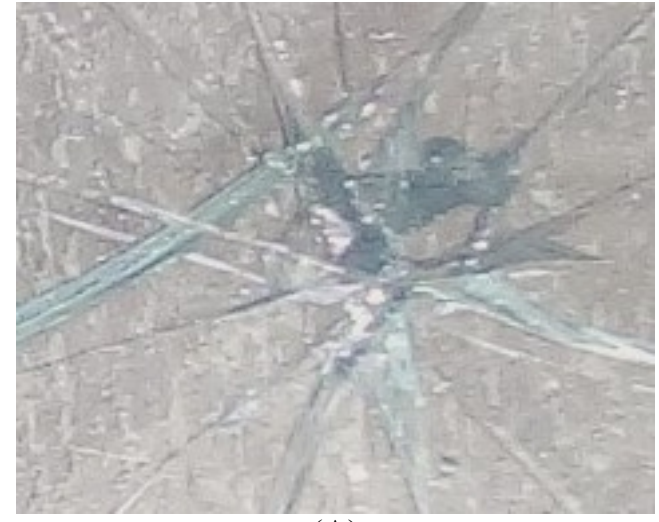

(A)

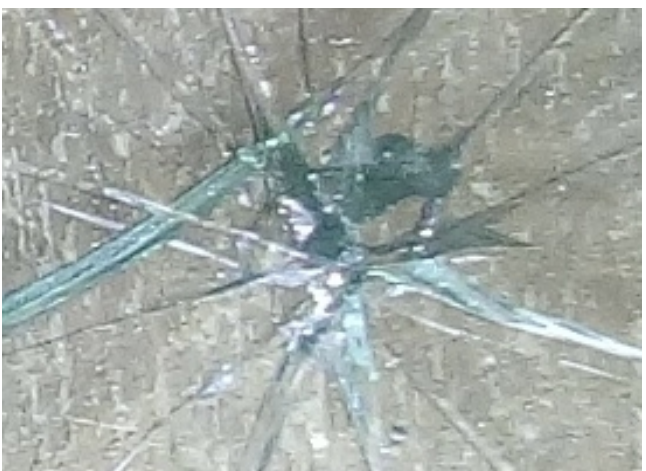

(B)

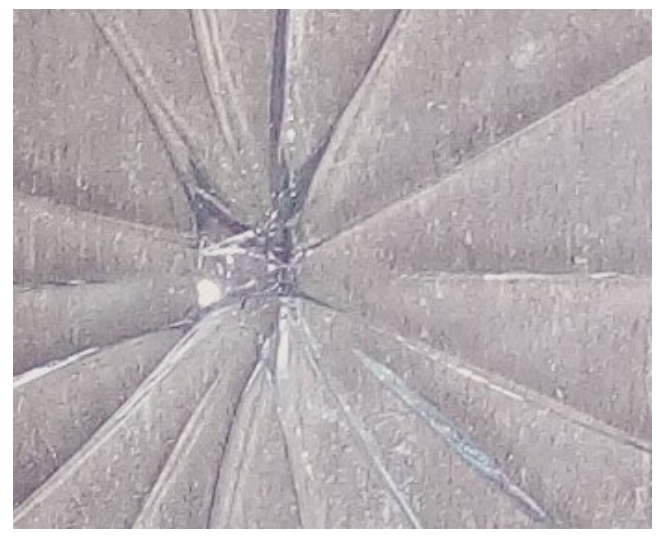

(C)

Fig. 3. Breaking patterns of (A) 60secs, (B) 180secs, and (C) 300 secs due to impact

\subsection{Flexural Strength Test}

The test was carried out using universal Testing Machine (Instron 3369, 50KN Load Capacity) with strain/Load rate of $5 \mathrm{~mm} / \mathrm{min}$. The laminated glass samples were cut into $145 \times 45 \mathrm{~mm}$ according to the specification of the flexural machine. The samples were then respectively placed on the two supporting rods of the machine one after the other in such a way that the projecting ribs of the samples had equal distance from the two supporting rods. Load was applied on the samples in such a way as to obtain a rate of increase of stress of $0.2 \mathrm{~N} / \mathrm{mm}$ per seconds. Load was applied to the sample until it fractured and the force at the point of fracture was noted.

\section{Results and Discussion}

\subsection{Impact}

From Table 2, it is observed that there is significant drop in the amount of impact energy that can be absorbed by the laminated glasses before breakage compared to the standard impact energy that can be absorbed by non- sandblasted glass according to [26]. This can be attributed to the effect of sandblasting causing strain on the glass thus reducing the impact strength.

Table 2. Result of Average Impact Strength of Laminated Samples

\begin{tabular}{lllll}
\hline Samples & $\mathrm{A}(60 \mathrm{secs})$ & $\mathrm{B}(180 \mathrm{secs})$ & $\mathrm{C}(300$ secs) & $\begin{array}{l}\text { Reference } \\
\text { (Nourry, } \\
\text { 2005) }\end{array}$ \\
\hline $\begin{array}{l}\text { Average } \\
\text { Impact } \\
\text { strength(J/M) }\end{array}$ & 35.42 & 36.14 & 34.01 & 170 \\
\hline
\end{tabular}

\subsection{Flexural Strength}

Table 3 shows the results of the flexural strength test. It is observed from the results that there is an immense reduction in the maximum flexural stress the sample glasses can absorbed before fracture in comparison with the reference value stated by [27]. This reduction in strength values of the sample laminated glasses can be attributed to eroding effects of sandstorms on the glasses as a result of lateral cracks and flaws formation on their surface which eventually serves as points of crack propagation during application of stress energy.

Table 3. Flexural strength

\begin{tabular}{|l|c|c|c|c|}
\hline Samples & A & B & C & $\begin{array}{c}\text { Reference } \\
\text { (Shaheda, } \\
\text { 2013). }\end{array}$ \\
\hline $\begin{array}{l}\text { Max. Flex. } \\
\text { Stress (MPa) }\end{array}$ & 2.21102 & 10.81438 & 10.00986 & 80 \\
\hline
\end{tabular}

\section{Conclusion}

In this present work, we simulated effects of sandstorms using sandblasting process on the laminated safety glass intended for automobile application in order to affirm the impart of sandstorms in real life situation in areas (Sahara regions) prone to such phenomenon in Nigeria. We have examined the influence of sandstorms duration, impingement angle, and impingement 
distance on impact and the flexural strength. The impart of sandblasting parameters on the automobile glass properties show there is immense drop in the impact resistance (impact strength) and flexural strength while highly blurred surface due to roughness which can impair optical quality is also observed.

\section{Acknowledgement}

The authors wish to express their profound gratitude to John Collins Glass Ltd., Nigeria for allowing us to utilize their machines for lamination of glasses and for the sand storming process.

\section{References}

[1] Faci, A., Kolli, M., Bouaouadja, N., Chabane, B., Study of the surface size defects in the case of a soda-lime glass eroded by sandblasting, in: MATEC Web of Conferences 5, 04038, 10.1051. 2013, 1- 3.

[2] Evans, A.G., Gulden, M.E., Rosenblatt, M., Impact damage in brittle materials in the elasticplastic response regime. Proc. R. Soc. London, Ser. A, 1978, 361, 343.

[3] Wiederhorn, S.M., Hockey, B.J., Effect of material parameters on the erosion resistance of brittle materials. J. Mat. Sci, 1983, 18, 766.

[4] Bousbaa, C., Madjoubi, M.A., Hamidouche, Z., Bouaouadja, N., Effect of sandblasting on sodalime glass properties. Engineering Journal of the University of Qatar, 2003, 16, 125- 138.

[5] Ritter, J.E., Strzepa, P., Jakus, K., Rosenfeld, L., Buckman, K.J., Erosion damage in glass and alumina. J. American Ceram. Society, 1984, 67, 769.

[6] Hutchings, I.M., Tribology, Friction and Wear Engineering Materials, Ed. Edward Arnold, 1992.

[7] Lawn, B.R., Marshall, D.B., Wiederhorn, S.M., Strength degradation of glass impacted with sharp particles: II, tempered glass. J. Amer. Ceram. Society, 1997, 62 [2-3], 71-74.

[8] Wada, S., Effect of the fracture toughness of impact particle on the erosive wears of ceramics, J. of the Jap. Soc. of Powder and Powder Metall., 1991, 38, 893-894.

[9] Wada, S., and Watanabe, N., Solid particle erosion of brittle materials - Part 4: The interaction with material properties of target and that of impingement particle on erosive wear mechanisms. Yogyo- Kyokai.Shi, 1987, 95 [6], 573-578.

[10] Slikerveer, P.J., Bouten, P.C.P., Scholten, H., Erosion and damage by sharp particles. Wear, 1998, 217, 237- 250.

[11] Slikkerveer, P.J., Bouten, P.C.P., Haas, F.C.M., High quality mechanical etching of brittle materials by powder blasting. Sensors and Actuators, 2000, 85, 296-303.
[12] Mahdaoui, T., Bouaouadja, N., Madjoubi, M.A., Bousbaa, C., Study of the effects of sand blasting on soda lime glass erosion. International Review of Mechanical Engineering, 2007, 1(5), 502-510.

[13] Belis, J., Depauw, J., Callewaert, D., Delincé and Van Impe, R., Failure mechanisms and residual capacity of annealed glass/SGP laminated beams at room temperature, Journal of Materials Science, 2008, 16, 1866-1875.

[14] Zang, M.Y., Lei, Z., and Wang, S. F., Investigation of impact fracture behavior of automobile laminated glass by $3 \mathrm{D}$ discrete element method, Springer Verlag, 2007.

[15] Keller, U., Measuring the delaminating energy in laminated safety glass, Proceedings of Glass Processing, Finland, 2005, 102-104.

[16] Asik, M.Z., and Tezcan, S., A mathematical model for the behavior of laminated glass beams. Computers and Structures, 2005, 83, 1742-1753.

[17] Foraboshi, P., Behavior and failure strength of laminated glass beams. Journal of Engineering Mechanics, 2007, 133 [12], 1290-1301.

[18] Shipway, P.H., Hutchings, I.M., The role of particle properties in the erosion of brittle materials. Wear, 1996, 193, 105-113.

[19] Yabuki, A., Matsuwaki, K., Matsumura, M., Critical impact velocity in the solid particles impact erosion of metallic materials. Wear, 1999, 233-235, $468-475$.

[20] Feng, Z., Ball, A., The erosion of four materials using seven erodents towards an understanding. Wear, 1999, 233-235, 674-684.

[21] Gulden, M.E., Effect of number of impacts on erosion of polycrystalline Mgf2 in the elasticplastic response regime. J. of the Amer. Ceramic Society, 1980, 63 [3-4], 121-126.

[22] Wheeler, D.W., and Wood, R.J.K., Solid erosion of diamond coatings under non normal impact angles. Wear, 2001, 250, 795-801.

[23] Shipway, P.H., and Hutchings, I.M., Influence of nozzle roughness on condition in a gas-blast erosion rig. Wear, 1993, 162-164, 148-158.

[24] Wada, S., Watanabe, N., Toshihiko, T., Solid particle erosion of brittle materials. J. of Seramikkusu Kyokai-Gakujustu-Ronbunshi, 1988, 96 [2], 111-118.

[25] Lawn, B.R., and Wilshaw, R., Review: Indentation fracture, principles and applications. J. Mat. Sci., 1975, 10 [6], 1049-1081.

[26] Nourry, E., Impact on laminated glass: postbreakage behavior sssessment, PhD thesis, SaintGobain, France, 2005.

[27] Shaheda, T.A. Mohammed, S.K., Characterization of laminated glass for structural applications, Msc thesis, Institutionen for Bygg-och Energiteknik, Linneuniversitetet, Sweden, 2013. 